\title{
Shared versus Specialized Glycinergic Spinal Interneurons in Axial Motor Circuits of Larval Zebrafish
}

\author{
James C. Liao and Joseph R. Fetcho \\ Department of Neurobiology and Behavior, Cornell University, Ithaca, New York 14853
}

The neuronal networks in spinal cord can produce a diverse array of motor behaviors. In aquatic vertebrates such as fishes and tadpoles, these include escape behaviors, swimming across a range of speeds, and struggling. We addressed the question of whether these behaviors are accomplished by a shared set of spinal interneurons activated in different patterns or, instead, involve specialized spinal interneurons that may shape the motor output to produce particular behaviors. We used larval zebrafish because they are capable of several distinct axial motor behaviors using a common periphery and a relatively small set of spinal neurons, easing the task of exploring the extent to which cell types are specialized for particular motor patterns. We performed targeted in vivo whole-cell patch recordings in $3 \mathrm{~d}$ post fertilization larvae to reveal the activity pattern of four commissural glycinergic interneuron types during escape, swimming and struggling behaviors. While some neuronal classes were shared among different motor patterns, we found others that were active only during a single one. These specialized neurons had morphological and functional properties consistent with a role in shaping key features of the motor behavior in which they were active. Our results, in combination with other evidence from excitatory interneurons, support the idea that patterns of activity in a core network of shared spinal neurons may be shaped by more specialized interneurons to produce an assortment of motor behaviors.

Key words: zebrafish; glycinergic spinal interneurons; axial motor patterns; spinal cord; motor; central pattern generator

\section{Introduction}

Animals can produce many different motor behaviors from the populations of neurons in the brain and spinal cord. There is good evidence from a variety of motor systems that individual neurons are sometimes shared across more than one type of behavior (Morton and Chiel, 1994; Marder and Calabrese, 1996; Xin et al., 1996; Kristan and Shaw, 1997; Berkowitz, 2005; Li et al., 2007). In other cases, however, neurons are not shared, but are specific to only one behavior (Shaw and Kristan, 1997; Berkowitz, 2002). How do we begin to make sense of this functional diversity? One strategy is to use a system in which we can unambiguously evaluate neuronal morphology, transmitter phenotype and behavior to ask which individual cell types are shared between behaviors and which are specific for a particular one. If we can understand the differences between shared versus specialized cell types, then we stand to gain broader insight into the design principles underlying neural circuits.

Some of the best understood vertebrate motor circuits are found in the spinal cord. In aquatic vertebrates, most studies of

Received July 16, 2008; revised 0ct. 19, 2008; accepted 0ct. 22, 2008.

This work was supported by a National Institutes of Health (NIH) National Research Service Award (J.C.L.) and NIH Grant NS26539 (J.R.F.). We thank S. Higashijima for generating the transgenic glycinergic line used in this study, Mark Masino and David McLean for providing helpful electrophysiology advice during the initial stages of the project, Amina Kinkhabwala, Minoru Koyama, and David McLean for providing critical feedback on this manuscript, Annie Hon and Lindsay Heller for excellent fish care, and all members of the Fetcho laboratory for their discussions throughout this project.

Correspondence should be addressed to Joseph R. Fetcho, Department of Neurobiology and Behavior, Cornell University, Ithaca, NY 14853. E-mail: jrf49@cornell.edu.

DOI:10.1523/JNEUROSCI.3330-08.2008

Copyright $\odot 2008$ Society for Neuroscience ～0270-6474/08/2812982-11\$15.00/0 motor circuits have focused on understanding the networks underlying particular axial motor behaviors, such as swimming and struggling in lampreys and frog tadpoles (Sillar and Roberts, 1992; Soffe, 1993; Roberts and Tunstall, 1994; Sigvardt and Williams, 1996; Yoshida et al., 1998; Li et al., 2007). Far less attention has been directed toward the question of the involvement of individual neuronal types in the generation of different motor patterns. Where this has been examined in aquatic vertebrates (Soffe, 1993; Berkowitz, 2002, 2005), the results have shown that classes of spinal neurons are commonly shared by different behaviors, although there is recent evidence in tadpoles that there are specialized cell types in rostral spinal cord (Li et al., 2007).

We have attacked the question of the differences between shared versus specialized cell types by taking advantage of the strengths of the larval zebrafish in which we can target genetically labeled cell types in spinal cord for recording and elicit a variety of axial motor patterns including swimming, struggling (described for zebrafish in this study) and escape (Hale et al., 2001; Higashijima et al., 2004b; McLean et al., 2007). These axial motor behaviors are shaped by spinal inhibitory interneurons that sculpt the motor pattern out of a tonic depolarization produced by descending excitatory interneurons (Fetcho, 1992). Some of the most important inhibitory interneurons in spinal motor networks are commissural because they are directly responsible for the patterns of alternation during the bending movements that underlie axial behaviors. We therefore focused on the question of the extent to which four major classes of spinal commissural inhibitory interneurons are shared or specialized for the three axial motor behaviors. Our work, along with data from excitatory spinal interneurons, support the conclusion that unique, behav- 
iorally specialized types of interneurons may shape the patterns of activity produced by a core of shared interneurons to produce specific motor behaviors.

\section{Materials and Methods}

Subjects. Experiments were conducted on 3 d post fertilization (dpf), transgenic larval zebrafish (Danio rerio) expressing green fluorescent protein (GFP) in glycinergic interneurons under the control of the Glyt2 promoter (McLean et al., 2007). Because struggling behavior (in which the body wave travels from tail to head) becomes increasingly harder to elicit in both the free-swimming and fictive preparation with age, this developmental stage was chosen to ensure that larvae would routinely exhibit struggling. All fish were reared in an in-house laboratory facility.

Electrophysiology. Larvae were anesthetized in a $0.02 \%$ solution of MS222 and then paralyzed by immersion in $1 \mathrm{mg} / \mathrm{ml} \alpha$-bungarotoxin (Sigma) in 10\% Hank's solution. Larvae were then placed in a dish containing extracellular solution (134 mM NaCl, $2.9 \mathrm{~mm} \mathrm{KCL}, 1.2 \mathrm{~mm} \mathrm{MgCl}$, $2.1 \mathrm{~mm} \mathrm{CaCl}_{2}, 10 \mathrm{~mm}$ glucose, $10 \mathrm{~mm}$ HEPES buffer, adjusted to a $\mathrm{pH}$ of 7.8 with $\mathrm{NaOH}$ ) and pinned through the notochord with four etched tungsten pins against a Sylgard base to position them on their side for recording (see Fig. 1A). Overlying skin and muscle were manually dissected away with an etched tungsten needle to expose 1-3 segments of spinal cord. GFP-labeled interneurons were imaged in vivo with a mercury lamp, a GFP bandpass filter cube (41017 EN GFP C62942, Omega Optical), and IPlab software (v3.7) controlling an integrating 12 bit mono CCD camera (QImaging) mounted on an upright Olympus BX51WI fixed stage compound microscope fitted with $10 \times$ and $40 \times(0.8$ numerical aperture, Olympus) water-immersion lenses. Whole cell patch recordings of interneurons (from segments 8-15) were conducted simultaneously with extracellular ventral motor root recordings (from segments 12-20) to monitor motor patterns. To test for possible adverse patch effects, we also performed cell-attached recordings to look at activity before breaking through and patching to confirm that activity patterns were not a result of damage from the patching process itself. On-cell and whole cell recordings led to similar results with respect to firing patterns. Both patch and ventral motor root electrodes were pulled from borosilicate glass (Model G150-F-3; inner diameter, $0.86 \mathrm{~mm}$; outer diameter, $1.5 \mathrm{~mm}$; Warner Instruments) on a Model P-97 Flaming/Brown micropipette puller (Sutter Instrument). Patch electrodes were pulled to 10-20 M $\Omega$ resistances and filled with $125 \mathrm{~mm} \mathrm{~K}$ gluconate, $2.5 \mathrm{~mm}$ $\mathrm{MgCl}_{2}, 10$ mм EGTA, 10 mм HEPES buffer, 4 mm Na 2 ATP, 0.1\% Sulforhodamine B (Sigma), and adjusted to a $\mathrm{pH}$ of 7.3 with potassium hydroxide. As in a previous study (Bhatt et al., 2007), the calculated junction potential using this recording solution was $16 \mathrm{mV}$, and we did not correct for it in the figures or reported potentials, so the reported values are 16 $\mathrm{mV}$ more positive than if they were corrected. Recordings were converted to digital signals (Axon Instruments Digidata 1322A) and amplified with a Multiclamp 700A amplifier (Axon Instruments) at a gain of 20 with a low-pass filter set at $30 \mathrm{kHz}$ with a sampling rate of $63 \mathrm{kHz}$.

After each recording, the key morphological features that define each cell type were confirmed by switching to a rhodamine filter set and an epifluorescence light source. A z-stack of images was collected by manual focusing and CCD image capture, and tracings were made directly from these images (Corel Draw v. 11). We only included cells filled well enough with dye to conclusively identify them based upon morphological features characteristic of the cell type. More detailed morphology of cell types and their processes were also obtained by injection of a BAC construct in which the glycine transporter 2 promoter (Glyt2) was driving GFP (50 ng/ $\mu \mathrm{l})$, into wild-type embryos at the one cell stage using a picoinjector (model PLI-100, Harvard Apparatus). Embryos were then screened at $3 \mathrm{dpf}$ for single-cell expression on a Leica MZ 16FA microscope. Selected larvae were then anesthetized in $0.02 \%$ MS-222 before embedding them in $1.4 \%$ low melting point agar (Fisher Scientific). High resolution, three-dimensional images of glycinergic interneurons were captured on a Zeiss LSM 510 inverted confocal microscope for comparison with patch-labeled cells. Similarly, potential postsynaptic targets were revealed by coinjection of the Glyt2 GFP to label interneurons and an Hb9 DsRed construct to label motoneurons (Arber et al., 1999).
Glass ventral root electrodes used to record motor activity were flame polished to $\sim 30 \mu \mathrm{m}$ diameter with a microforge (MF-830 Narishige International) and placed on the myotomal clefts. Recordings were amplified at a gain of 1000 with a low pass filter set at $5 \mathrm{kHz}$ and a high-pass filter set at $50 \mathrm{~Hz}$. Motor patterns were elicited by a brief electrical stimulus to the head (see Fig. $1 \mathrm{~A}$ ) via tungsten electrodes $(0.005$ inch, 8 degrees, A-M Systems) connected to an isolated stimulator (Model DS2 Digitimer). Escapes were generated with a single, large electrical impulse $(20-50 \mathrm{~V}, 0.2 \mathrm{~ms})$. Swimming was generated with single pulses across a range of voltages $(10-20 \mathrm{~V}, 0.2 \mathrm{~ms})$, and the frequency of swimming increased with voltage amplitude. Struggling was elicited with 3-10 lowfrequency, low-amplitude pulses (1-20 V, $0.2 \mathrm{~ms}, 0.5-5 \mathrm{~Hz})$. Several minutes rest was allowed between stimulus trials to generate the entire range of motor patterns for each larva. Experimental procedures were approved by the Cornell University Institutional Animal Care and Use Committee.

Analysis. Neuronal activity was recorded with pClamp v9.2, analyzed off-line with Dataview (Dr. William Heitler, University of St. Andrews, St. Andrews, UK) to measure burst durations and relative timing, and plotted in Matlab v. 7.0. Interneuron activity was defined by a minimum of one spike during a relevant ventral motor nerve burst. An action potential was defined as a fast event with a duration of $\sim 1$ millisecond, and could exhibit a range of potential amplitudes depending on the cell type (some spikes were overshooting zero while others were relatively small; these differences are discussed later). Although we defined firing by at least one action potential (the least possible), unless otherwise noted (as for CoSAs), neurons that we concluded were involved in swimming or struggling fired on multiple cycles in at least some bouts, so they were not simply firing once in a behavior. A trial was defined as one successfully elicited motor behavior. For each of the four cell classes, the percentage of trials in which an individual cell was active during each behavior (3-10 trials for swimming, 1-10 trials for escapes and struggling) was calculated for each cell first, and then averaged for all cells in the class. All values reported are means plus or minus the SD of the mean. Paired $t$ tests for swimming and struggling burst statistics were performed in Matlab with a significance level set at $p<0.001$ and were Bonferroni-corrected for multiple comparisons.

\section{Results \\ Characteristics of fictive escape, swimming and struggling behaviors}

Three distinct axial motor patterns were observed in our fictive zebrafish preparation. An escape response (Fig. $1 B$ ), followed by swimming bursts, was characterized by a single, brief short latency burst of ventral motor root activity typically $<20 \mathrm{~ms}$ from the onset of a contralateral electrical stimulus (Liu and Fetcho, 1999). Fictive swimming showed rhythmic bursts of ventral motor root activity that traveled from head to tail (Fig. 1C). The pattern was consistent with the rostrocaudal propagation of bending and the duration of swimming episodes characteristic of freely swimming animals (Fig. $1 E$ ). When freely behaving animals struggle, the amplitude of the body wave increases compared with swimming and the wave direction reverses to travel from tail to head (Fig. 1D,F). In our fictive preparations, struggling was identified by motor bursts that propagated from tail to head and that were longer in duration and lower in frequency than swimming, although with a shorter overall episode length. Our initial recordings were made from two ventral root electrodes placed apart along the body to confirm the direction of the body wave critical to distinguishing swimming from struggling. We found that struggling bursts were consistently different enough from swimming bursts to easily distinguish them even within a single root recording (see $1 \mathrm{G}$ ). In later experiments, we therefore used single ventral root recordings combined with single cell patch recordings, which simplified the overall process. 
A

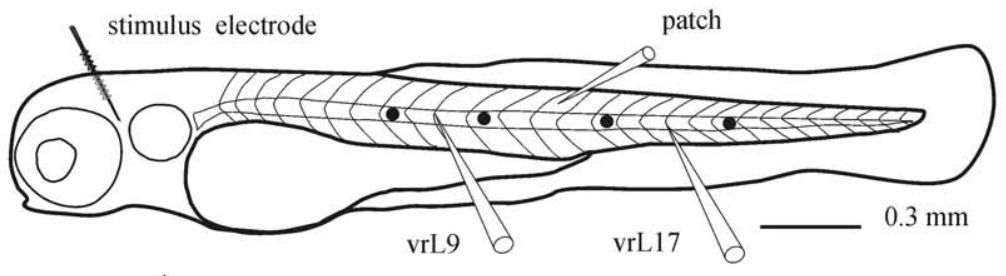

B

C

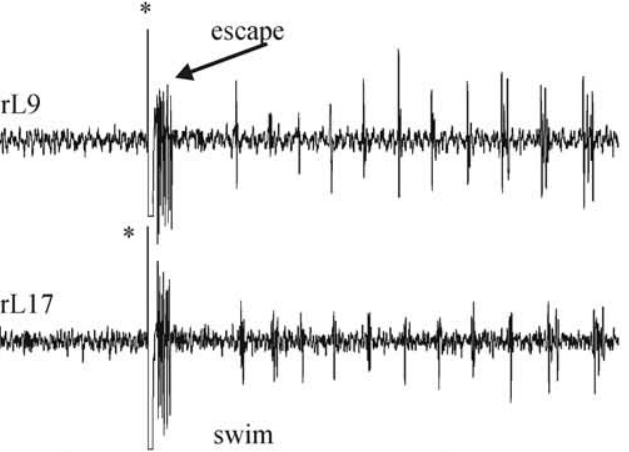

D

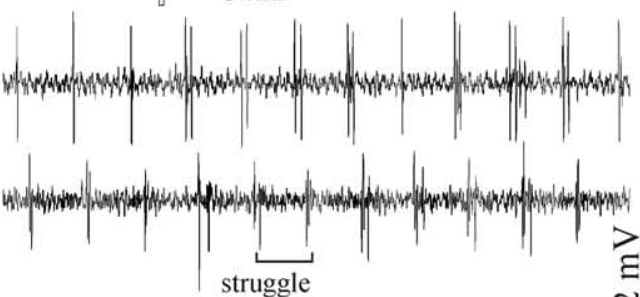

G
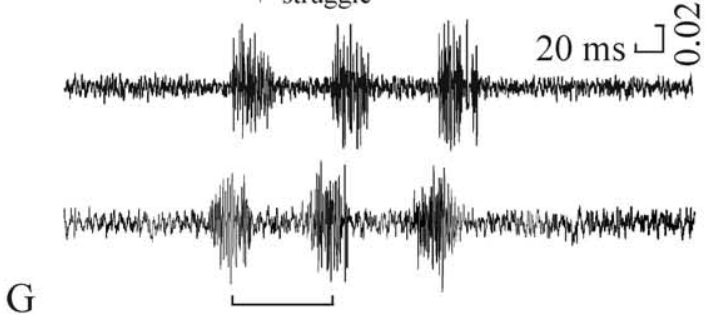

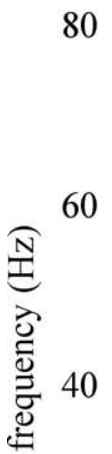
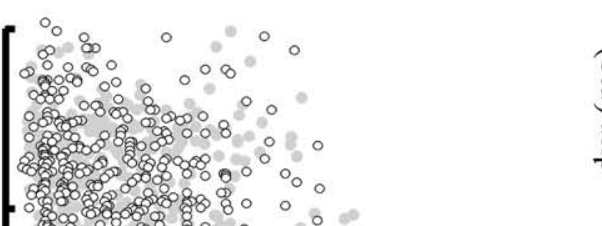

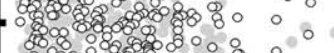
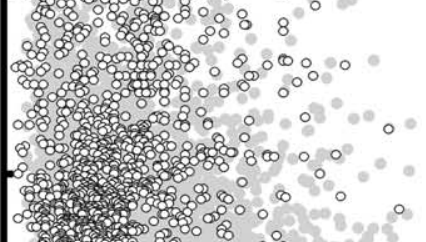

E

F

swim

struggle
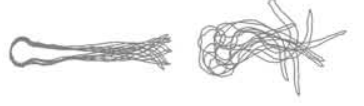

$\infty$
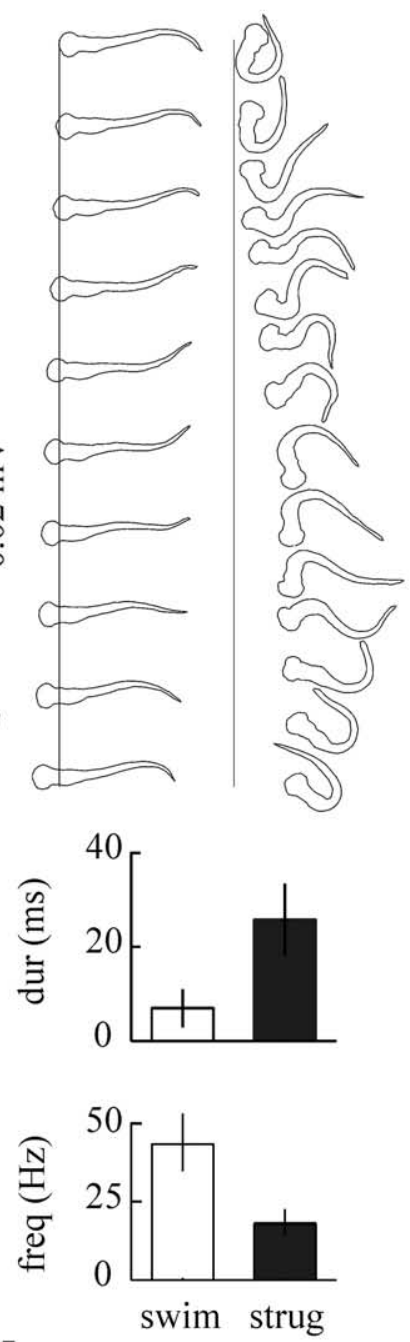

20

single VR strug ( $($ ) swim (o)

paired VR strug (-) swim (o)

0

0

10

20

30

40

50
Activity of commissural

glycinergic interneurons

Targeted whole-cell patch recordings were made from 153 commissural glycinergic spinal interneurons in the transgenic Glyt2-GFP line (McLean et al., 2007) while escape, swimming, and struggling motor patterns were elicited. We divided all of the cells into four classes based on unique features of their morphology visible in the rhodamine filled patched cells, in accord with previous data on morphology and transmitter phenotype (Hale et al., 2001; Higashijima et al., 2004a,b). The following sections deal in turn with each type.

\section{Commissural longitudinal} ascending interneurons

The 23 commissural longitudinal ascending interneurons (CoLA) neurons examined here had the largest somata of all the glycinergic cell types we recorded. They had the second highest firing threshold of all the cells examined here (Fig. 2Ai) $(-12.2 \pm 2.7 \mathrm{mV})$, and fired repetitively in response to depolarizing current injections. Of all 23 cells tested, 8 showed evidence of spike frequency adaptation.

The first description of CoLA morphology was based on a retrograde labeling technique and revealed an ascending axon of five segments or less (due to the inability to label from further away) and a short descending branch (Hale et al., 2001). In this study we were able to obtain more detailed morphological information from our dye-labeled, single cell patch recording technique and transient expression of GFP. The key morphological characteristics that defined CoLAs were that they had a large, pyriform cell body with a characteristic dorsal dendrite that projected caudally from the somata and a short ipsilat-

\footnotetext{
propagation of motor activity with substantially longer interburst intervals (brackets) and burst durations than swimming. Stimulus occurred $153 \mathrm{~ms}$ before the first motor burst (data not shown). Panels B-D are from the same animal. Kinematics of swimming $(\boldsymbol{E})$ and struggling $(\boldsymbol{F})$ illustrating the difference in body amplitude and wavelength between the two behaviors. Digital images were captured with a highspeed video camera (250 frames/s) and outlines were generated using a custom written Matlab program. G, Scatter plot showing that frequency and duration of swimming (gray circles, $n=4847$ trials) and struggling (gray squares, $n=393$ trials) bursts from a single ventral motor root electrode are similar to paired ventral root recording of swimming (open circles) and struggling (black squares). Inset graphs show that average swimming burst duration was significantly shorter $(p<0.001)$ than struggling burst duration $(5.6 \pm 3.6 \mathrm{~ms}$ vs $26.2 \pm 7.2 \mathrm{~ms})$, and that average swimming frequency was significantly higher $(p<0.001)$ than struggling frequency $(42.7 \mathrm{~Hz} \pm 12.2$ vs $18.5 \mathrm{~Hz} \pm 3.5)$.

Figure 1. A, Experimental setup showing placement of electrical stimulus, patch clamp and ventral motor root electrodes, and tungsten holding pins (black circles) on a $3 \mathrm{dpf}$ zebrafish larva. $\boldsymbol{B}$, Paired ventral motor root recordings (segments 9 and 17) of the escape response (arrow) show near simultaneous left side motor activity immediately following a right side electrical stimulus ( ${ }^{*}$ stimulus artifact). C, During swimming, rhythmic bursts of motor activity propagate from head to tail in response to an electrical stimulus $57 \mathrm{~ms}$ before the first motor burst (off the page to the left of trace, data not shown). $\boldsymbol{D}$, Struggling involves a caudorostral 

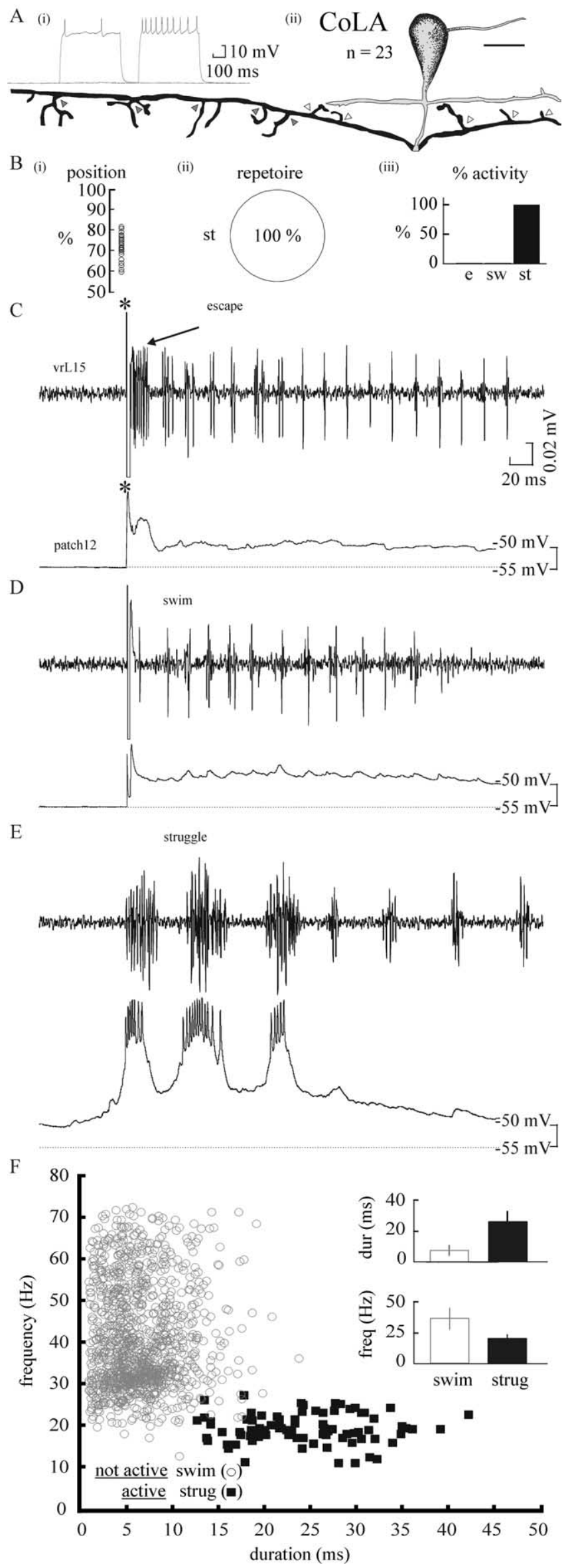

eral ascending and descending dendrite that bifurcated from the main ventral process (Fig. 2Aii). The somata were located between 59 and $81 \%$ from the bottom of the cord with an average of $71 \%$ (Fig. 2 Bi). The main axon of a CoLA crosses in the spinal cord and then branches into a long ascending axon $(>10$ segments) that rises dorsally as it extends toward the hindbrain, and a short descending axon that typically spans less than one segment. Close to the soma, the ascending axon gave rise to processes that extended dorsally, while further away, these processes flipped to extend ventrally. This morphology strongly suggests potential postsynaptic contacts in the mid-dorsal region of cord.

To examine possible contacts with motoneurons we transiently expressed an Hb9 GFP and a Glyt2 DsRed construct to label motoneurons and glycinergic neurons respectively. In six animals we were able to see swellings of processes of DsRed labeled CoLA neurons in apposition to the somata of GFP filled motoneurons, consistent with the possibility of synaptic contacts from CoLA neurons onto motoneurons (Fig. $3 A$ ). Confocal z-stack images were viewed in multiple orthogonal planes to confirm that processes stemming off the ascending axon surrounded and made contact with other spinal neurons. Our method of labeling allowed us to identify primary motor neurons as well as occasionally colabeled commissural bifurcating longitudinal interneurons (discussed later) that had contacts from CoLAs. Together, the unique morphology and specific activity pattern of CoLAs suggests that they could receive input across several dorsoventral levels of cord and are poised to coordinate predominantly rostral inhibition.

Physiologically, the CoLA neurons were unique in that they never fired during escapes or swimming, but only during struggling (Fig. 2 Bii). CoLAs fired every time struggling behavior was elicited (Fig. 2 Biii). While small membrane depolarizations were evident during escapes (Fig. 2C) and swimming (Fig. 2D), multiple action potentials were generated on top of a depolarized plateau potential during struggling (Fig. $2 E$ ). No activity was recorded when swimming behavior with frequencies from 20 to $70 \mathrm{~Hz}$ was elicited, whereas during struggling, the neurons were active in every episode and over the range of burst parameters seen during this behavior (Fig. $2 F$ ).

$\leftarrow$

Figure 2. CoLAs are active only during struggling. Ai, Depolarizing current injections showing tonic spiking with spike frequency adaption. Aii, Tracing in a lateral view of spinal cord (rostral to the left) illustrates the large, tear-drop shaped soma from which a prominent caudal dendrite extends. The ascending axon sends dorsal processes (white triangles) proximal to the soma and ventral processes (gray triangles) distal to the soma, presumably to contact postsynaptic targets in the mid-lateral region of the cord (black indicates contralateral portions of the axon). $\mathbf{B i}$, The average dorsoventral position of the somata in the cord is $71 \%$, where $100 \%$ represents the dorsal edge of the spinal cord. Bii, Pie chart illustrating the percentage of cells active during a particular motor pattern or repertoire of motor patterns. CoLAs are active only during struggling (st) and not during swimming and escapes. Biii, Graph showing that CoLAs fire during all struggling trials elicited. C, Simultaneous whole-cell (bottom, segment 12) and ventral motor root (top, segment 15) recordings show that CoLAs depolarize but do not fire during an escape behavior (arrow) in response to an electrical pulse (*stimulus artifact). Note that an episode of swimming follows the escape response. D, During swimming CoLAs show a depolarized membrane potential but do not fire action potentials. $E$, CoLAs fire multiple spikes on top of depolarized plateau potentials during struggling, but stop firing when the motor pattern transitions to swimming. Stimulus occurs $87 \mathrm{~ms}$ before the first motor burst (to left of trace, data not shown). $\boldsymbol{F}$, Plot of motor root duration and frequency along with average values \pm SDs (inset graphs) for swimming (circles; tested duration $=6.4 \pm 3.5 \mathrm{~ms}$, tested frequency $=34.7 \mathrm{~Hz} \pm 8.9$ ) and struggling ( squares; duration $=25.1 \pm 6.7 \mathrm{~ms}$, frequency $=$ 18.3) for all cells for all trials. Black fill indicates that the cell fired an action potential during the behavior while a gray outline indicates that the cell did not fire. CoLAs fire during struggling over its burst range (filled squares) but not during swimming (open circles). All electrophysiology traces are from the same cell. 

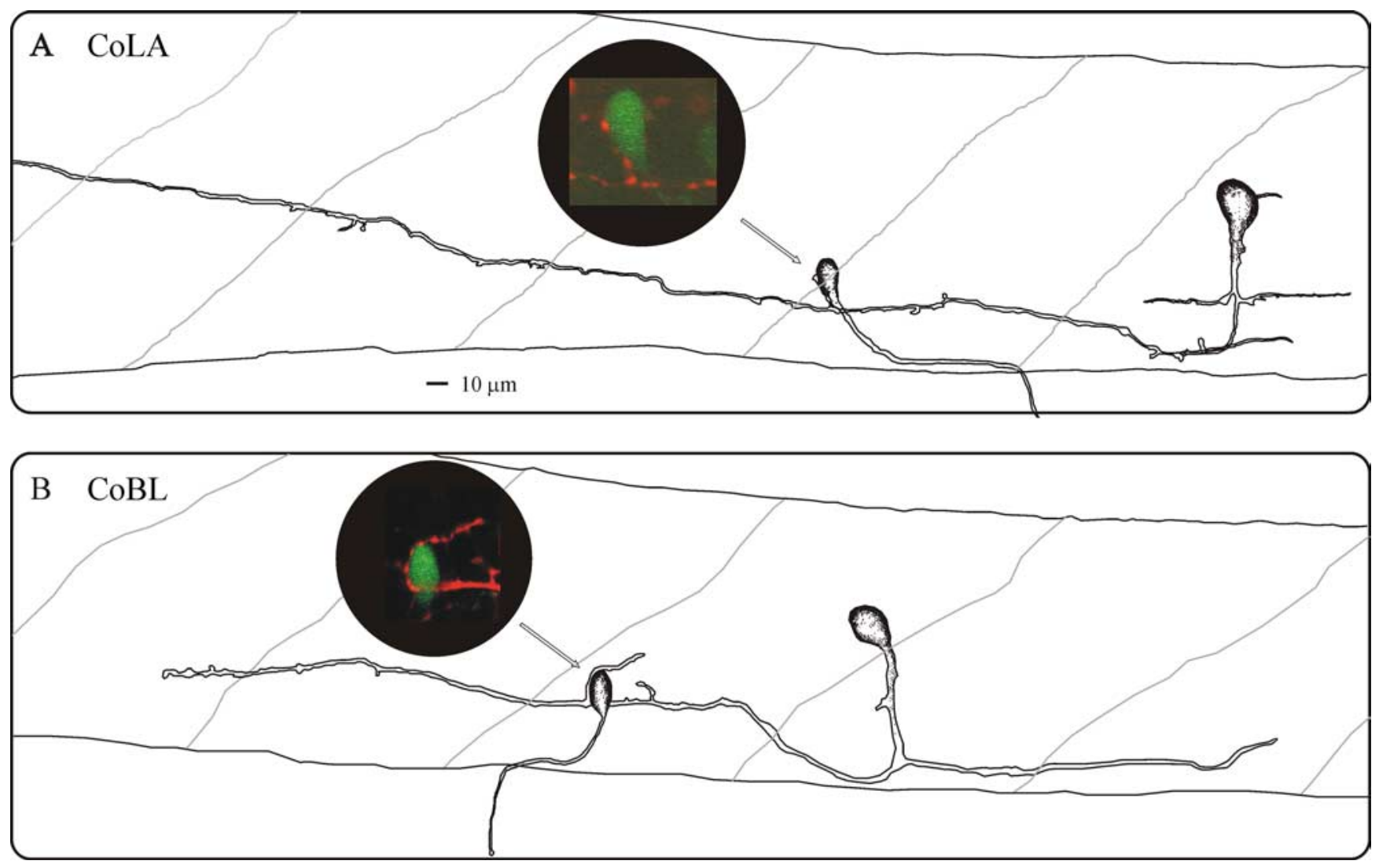

Figure 3. Tracing of a $\mathrm{COLA}(\boldsymbol{A})$ and $\mathrm{COBL}(\boldsymbol{B})$ interneuron along with their potential postsynaptic motoneuron, generated from a confocal $z$-stack image of a wild-type embryo coinjected with the Hb9 GFP and Glyt2 DsRed construct. Close-up images (arrows) from single 0.85 micron slices show boutons of the ascending glycinergic axons of each neuron (red) surrounding the motoneuron soma (green).

\section{Commissural local interneurons}

Commissural local interneurons (CoLos) are a previously undescribed cell type in zebrafish and had the highest firing threshold of all of the cells investigated (Fig. $4 A i)(-2.1 \pm 7.4 \mathrm{mV})$. Unlike all other cells described here, which fire repetitive action potentials in response to a depolarizing current, the 34 CoLos we recorded from usually fired a single, small amplitude spike. The small spike amplitude was likely the result of the spike initiating region being located at a relatively large distance from the recording site at the soma, since previous evidence from tench and goldfish indicates that a similar cell type is driven by gap junctional inputs from the Mauthner axon that are located on the first node of Ranvier of the axon, and that the CoLo-like neurons have little input on the soma (Fetcho, 1990; Yasargil and Sandri, 1990). There is also a very thin process connecting to the soma of CoLos and the comparable neuron in goldfish, so that a distally initiated action potential might be much attenuated at the soma. The small potentials in CoLos were not likely due to damage from patching since in our cell-attached tests they were not evident as large currents.

CoLos had a simple, spherical soma with no obvious dendrites and an axon, thin initially, which extended ventrally before crossing the cord (Fig. 4Aii). Upon crossing cord, CoLos sent a characteristically short ( $\sim 1$ body segment), robust, descending axon that ran parallel to and near the Mauthner axon. Some cells had an additional, relatively short ascending branch. Their cell bodies were located between 61 and $83 \%$ of the cord with an average of $71 \%$ (Fig. $4 \mathrm{Bi}$ ).

CoLos are unique in that they only fired during escapes. Thirty of 34 cells ( $88 \%$ ) fired during at least one escape behavior (Fig. $4 \mathrm{Bii}$ ). The percentage of times these 30 cells fired during an escape response was determined for each cell and then averaged across cells. This showed that on average the cells fired during $55 \%$ of the elicited escapes (Fig. 4 Biii). Four cells did not fire during any of the three behaviors (12\%). During escapes, CoLos showed short latency, small amplitude spikes recorded at the soma (Fig. 4C) during the initial escape burst. These neurons were not active during swimming over a broad range of swimming frequencies (Fig. $4 F$ ) and sometimes received mid-cycle inhibition (Fig. 4D). They were also never active during struggling over its normal range of burst parameters (Fig. $4 F$ ).

\section{Commissural secondary ascending interneurons}

Commissural secondary ascending interneurons (CoSAs) are traditionally thought to be morphologically related to commissural primary ascending interneurons (CoPAs, a glutamatergic sensory reflex interneuron), but are later developing. Hence, CoPAs and CoSAs were named accordingly as primary and secondary cell types to reflect this perceived relationship (Bernhardt et al., 1990). However, in situ staining has shown that there are at least two CoSA phenotypes that express either glutamatergic or glycinergic transmitters (Higashijima et al., 2004b). Here we focus on glycinergic CoSAs, which are presumably functionally different from the glutamatergic ones.

CoSAs fire tonically upon current injection and have the lowest firing threshold of all the interneurons studied here (Fig. 5Ai) $(-26.9 \pm 4.9 \mathrm{mV})$. Upon crossing the spinal cord dorsal to the Mauthner cell axon, CoSAs send a long axon ( $>10$ segments) 


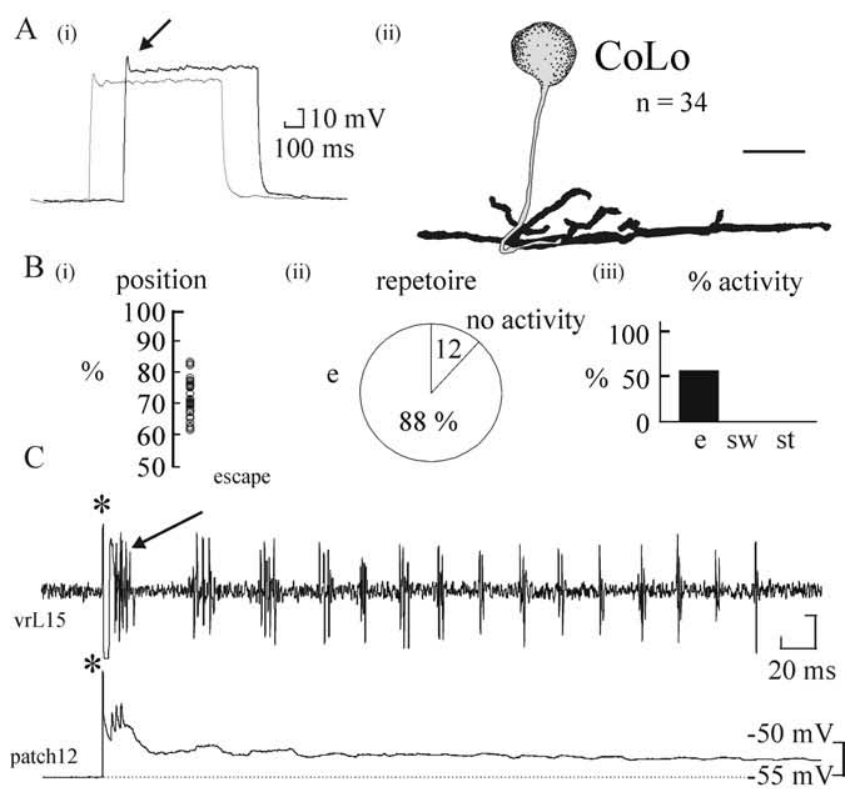

$\mathrm{D}$

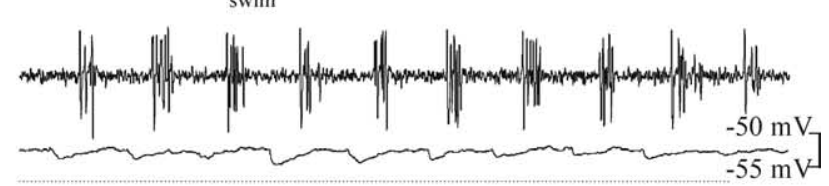

E

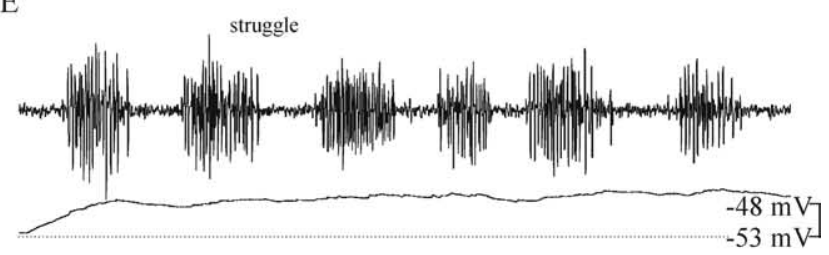

$\mathrm{F}$

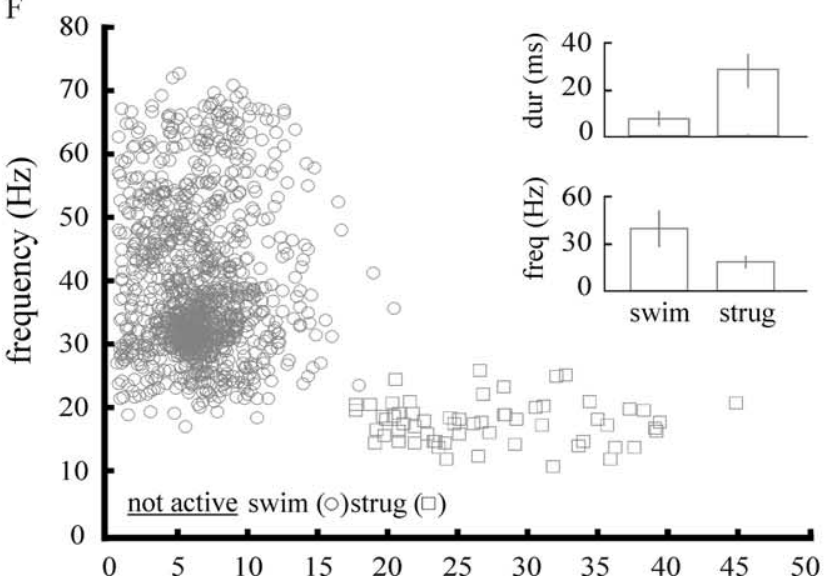

Figure 4. CoLos are active only during escapes. Ai, Depolarizing current injections showing a single, small amplitude spike (arrow) once threshold is reached, probably small because the spike-initiation site is located relatively far away from the soma (see Results, Commissural local interneurons). Aii, Tracing of a CoLo in a lateral view of spinal cord (rostral to the left) showing a short descending axon with multiple processes, which runs parallel to the Mauthner axon (black portions are contralateral). Bi, The average dorsoventral position of CoLos in the spinal cord is $71 \%$, where $100 \%$ represents the dorsal edge of cord. (ii) Pie chart illustrating that CoLos fire only during escapes (e) and not during swimming (sw) or struggling (st). Note that a fraction of CoLos showed no activity during any motor pattern in the trials examined. (iii) Graph showing that CoLos fired $55 \%$ of the time that an escape behavior was elicited (averaged over the 30 cells that showed activity). C, Simultaneous motor root and whole-cell recordings of a CoLo firing small-amplitude action potentials during an escape behavior (arrow) in response to an electrical pulse ( ${ }^{*}$ stimulus artifact). CoLos do not fire during swimming ( $\boldsymbol{D}$; stimulus occurs $59 \mathrm{~ms}$ before first motor burst) or struggling (E; stimulus occurs 28 ms before first motor burst)). $\boldsymbol{F}$, Plot that ascends dorsally (Fig. 5Aii). CoSA somata are located the most dorsally of all the cells studied here (70-92\% of the spinal cord with an average of $80 \%$ ), consistent with the idea that CoSAs may receive sensory input like CoPAs (Hale et al., 2001).

We found CoSAs to be functionally the most heterogeneous cell type. While the cells showed diverse patterns nearly all CoSAs fire during swimming, around two-thirds also fire during struggling and a few also fire during escapes. Of the 21 glycinergic CoSAs that we targeted, five were active during the initial escape burst $(23.8 \%)$, but were active in other behaviors as well (Fig. 5 Bii). This subset of CoSAs was active during $19 \%$ of all trials for which an initial escape burst was elicited (Fig. 5Biii,C). Nineteen of the 21 CoSAs fired at least one action potential during swimming $(90.5 \%)$. Of these cells, $26.5 \%$ fired once during the first swim cycle (Fig. $5 D$ ), while the majority $(73.5 \%)$ fired 3 or more action potentials that carried into the middle or end of the bout (supplemental Fig. 1, available at www.jneurosci.org as supplemental material). Firing a single action potential occurred during lower average swimming frequencies $(37.3 \mathrm{~Hz} \pm 4.3)$ than multiple firing $(46.1 \mathrm{~Hz} \pm 8.0)$ reflecting that in some cases neurons became rhythmically active at higher frequencies. Cells which fired at least one action potential during swimming were active during $52 \%$ of all swimming trials elicited. Four of 21 cells were active only during swimming (19\%). Sixteen cells fired during struggling $(76.2 \%)$, and these cells were active during $62 \%$ of all struggling trials elicited. Three CoSAs were active during escapes, swimming, and struggling (14.3\%). Eleven CoSAs were active during swimming and struggling only $(52.4 \%)$. One CoSA was active during escapes and swimming (4.8\%), one CoSA was active during escapes and struggling and one CoSA was active only during struggling.

The relationship between CoSA activity in the ventral root bursts could vary. Some CoSAs fired action potentials that did not coincide with motor root activity at slow swimming frequencies, typically occurring at the beginning of swimming bouts. This was not the case during struggling, when CoSA action potentials were repetitive and tightly synchronized to motor root activity (Fig. 5E). Although some CoSAs did not fire during both swimming and struggling, the ones that did showed activity that together spanned the entire range of burst parameters recorded for these motor patterns (Fig. $5 F$ ).

\section{Activity in commissural bifurcating longitudinal interneurons}

Commissural bifurcating longitudinal interneurons (CoBLs) were the most common cell type encountered in our recordings and showed the most morphological diversity. Because they were so common, we recorded from many more CoBLs than other cell types $(n=75)$. CoBLs fired repetitive action potentials with no spike frequency adaptation in response to depolarizing current injections, with an average firing threshold of $-20.8 \pm 6.3 \mathrm{mV}$ (Fig. 6Ai).

CoBL axons crossed the ventral spinal cord and then bifurcated into an ascending and descending branch (Fig. 6 Aii). The lengths of these branches varied widely; some had axons that spanned little more than one segment while others spanned $>10$

$\leftarrow$

of tested motor root burst duration and frequency along with average values \pm SDs (inset graphs) for swimming (open circles; duration $=6.8 \pm 3.0 \mathrm{~ms}$, frequency $=38.6 \mathrm{~Hz} \pm 11.7$ ) and struggling (open squares; duration $=27.7 \pm 6.8 \mathrm{~ms}$, frequency $=17.7 \mathrm{~Hz} \pm 3.6$ ) for all cells in all trials to show the range tested, over which no activity was found. All electrophysiology traces are from the same cell. 

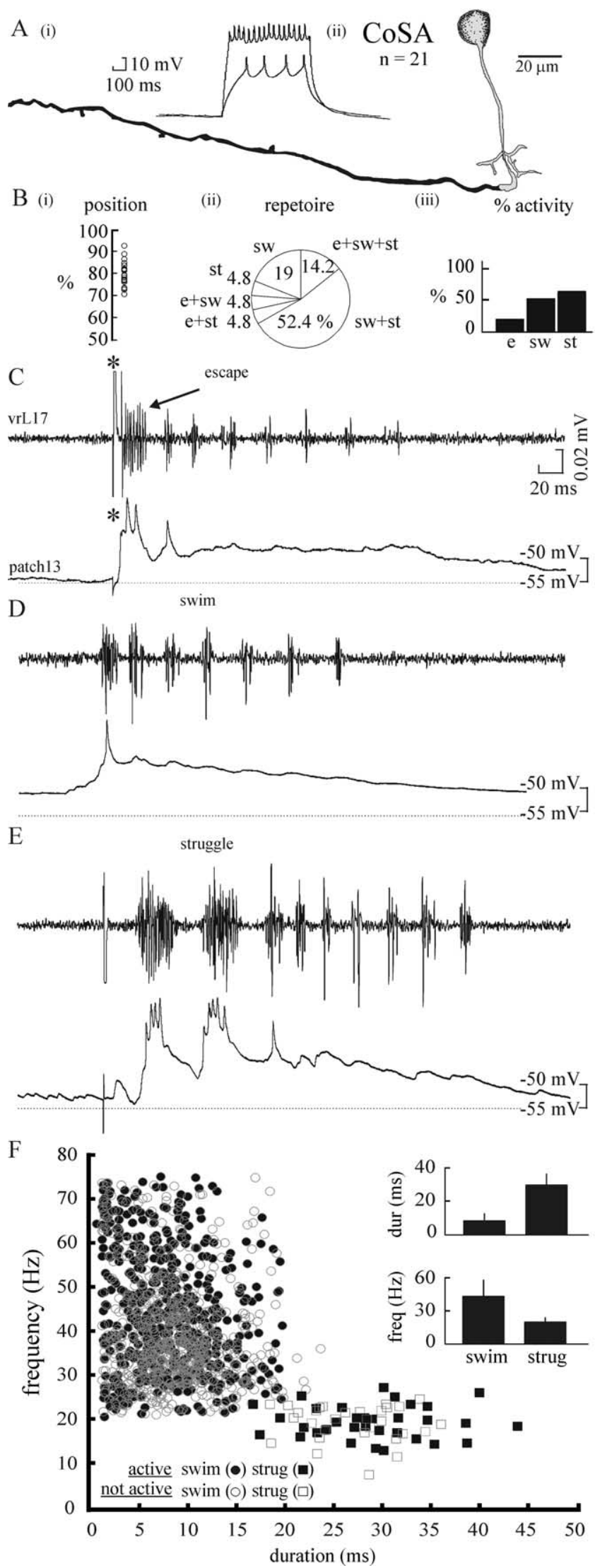

Figure 5. CoSAs are multifunctional. Ai, Depolarizing current injections show tonic spiking near threshold and above. Aii, Tracing in a lateral view of spinal cord (rostral to the left) showing ipsilateral dendrites distal to the soma. The main axon hooks caudally before crossing to ascend (black portions are contralateral). Bi, Dorsoventral position of the somata in the cord, where segments. CoBL cell bodies were located between 51 and 91\% from the bottom of the cord, with an average of $73 \%$ (Fig. $6 \mathrm{Bi}$ ).

Coinjection of the Hb9 GFP and Glyt2 DsRed promoter constructs into wild-type embryos and subsequent confocal imaging of multiple orthogonal planes allowed us to visualize closely apposed contacts of both the ascending and descending axons of CoBLs with the somata of primary motor neurons (Fig. 3B).

Most CoBLs were active during swimming and struggling, but rarely during escapes (Fig. 6A-E). Only 3 of 75 CoBLs (4\%) were active during the escape response, compared with $100 \%$ for swimming and $88 \%$ for struggling (Fig. 6 Bii). Escape CoBLs fired at least one spike during $3 \%$ of all escape trials elicited (Fig. 6 Biii), and the spiking typically occurred early in an experiment. All CoBLs fired during at least some swimming episodes, but when pooled together they were active in only $49 \%$ of the trials. This was due largely to the finding that ventrally located CoBLs will only fire at higher swimming frequencies (Fig. 6D) (McLean et al., 2007). Six of 75 cells were active only during swimming (8\%), and not during struggling or escapes. Struggling CoBLs fired multiple action potentials that rode on top of strong depolarizing potentials during $81 \%$ of all trials for which struggling was elicited (Fig. 6E, where struggling is followed by swimming). As a group of interneurons, CoBLs fire across the entire range of burst statistics for both swimming and struggling (Fig. $6 F$ ) and all cells could fire rhythmically during at least some episodes of both behaviors.

\section{Discussion}

Swimming, struggling, and escape behaviors all share the fundamental building block of ipsilateral muscle contraction with simultaneous blocking of contralateral muscle activity. However, the timing and pattern of coordination along the body differs considerably between these behaviors. Swimming occurs over a broad range of speeds, struggling involves a complete change in the direction of body wave propagation and escapes demand very fast, nearly synchronous whole body contraction. Our results suggest that these behaviors are generated not simply through a reorganization of a common pool of spinal interneurons, but by the recruitment of specific glycinergic cell types.

The differences in motor pattern between swimming and struggling are dramatic and their potential neural basis has been explored in previous work. During swimming, higher levels of excitation in the anterior spinal cord relative to caudal cord are thought to generate head to tail traveling body waves (Roberts and Tunstall, 1994; Tunstall and Roberts, 1994; Roberts et al.,

$100 \%$ represents the dorsal edge of the spinal cord. CoSAs have the most dorsal positions in the cord (80\%) of all cells in this study. Bii, As a group, CoSAs are active during all three motor patterns tested, with the majority of cells firing to both swimming (sw) and struggling (st) and a smaller percentage during escapes (e). Biii, Graph showing the percentage of times that CoSAs fired when escape (19\%), swimming (52\%) and struggling (62\%) motor patterns were elicited. $C$, Simultaneous motor root and whole-cell recordings of a CoSA firing during an escape behavior (arrow) elicited by an electrical pulse (*stimulus artifact), followed by swimming. $\boldsymbol{D}$, CoSAs usually fire a single spike at the beginning of slower swimming frequencies (stimulus occurs to left of trace, 63 ms before first motor burst, data not shown), in contrast to multiple spikes fired during struggling $(\boldsymbol{E})$. $\boldsymbol{F}$, Plot of motor root duration versus frequency for swimming (circles) and struggling (squares) for all cells for all trials. Black filled symbols indicate that the cell fired, while gray outlined symbols indicate that the cell did not fire. Due to the heterogeneity of CoSA functionality, these values overlap frequently. Average duration and frequency values \pm SDs (inset graphs) are shown for the trials in which the cell fired an action potential during swimming (duration $=7.6 \pm 4.4 \mathrm{~ms}$, frequency $=43.1 \mathrm{~Hz} \pm 13.4$ ) and struggling (duration $=28.4 \pm 6.4 \mathrm{~ms}$, frequency $=18.8 \mathrm{~Hz} \pm 3.6$ ). All electrophysiology traces are from the same cell. 


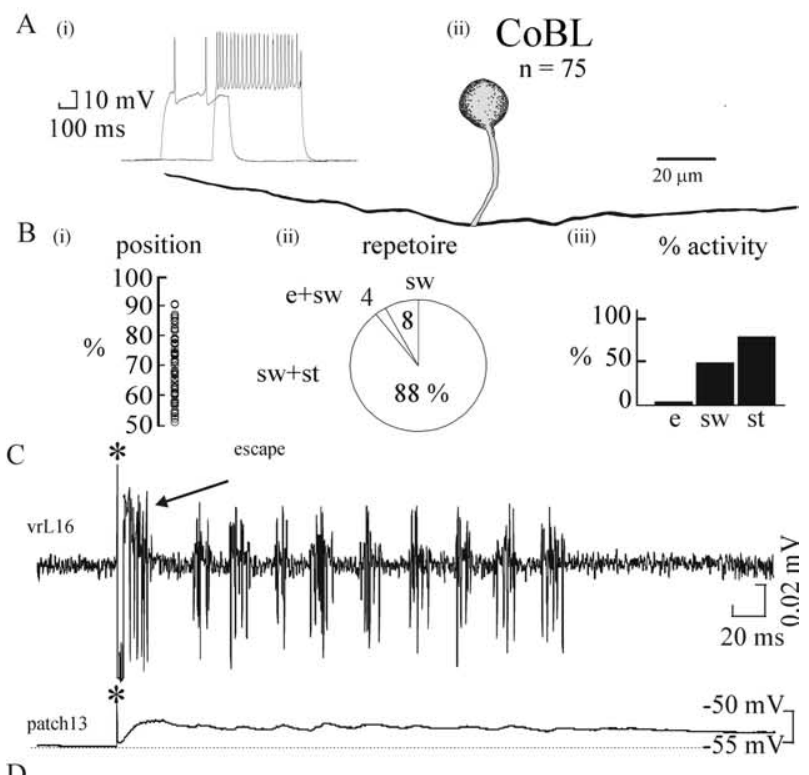

D
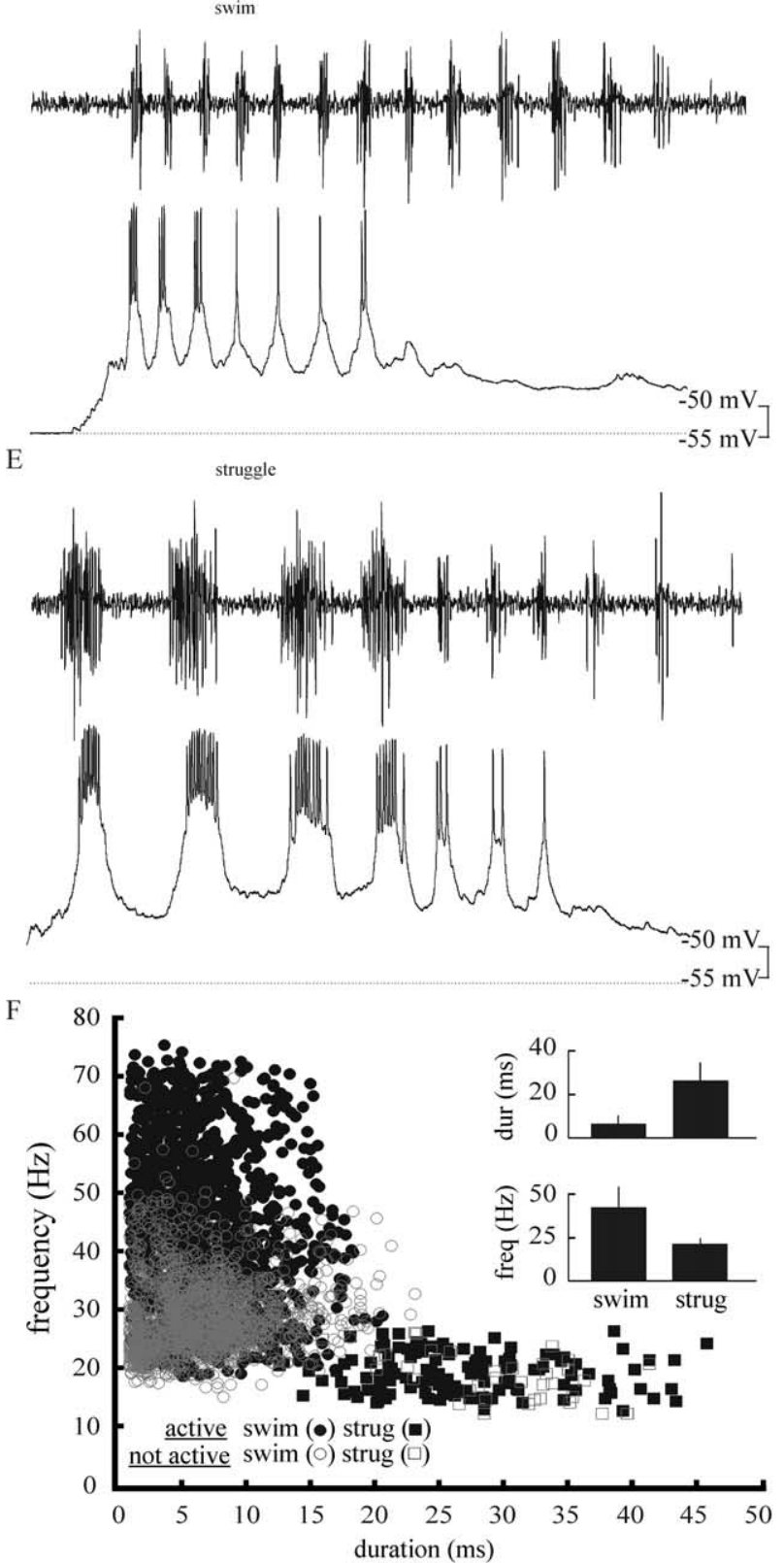

1999). A change to a higher excitability caudally can change the direction of propagation, leading to waves from tail to head, as in struggling (Tunstall and Roberts, 1991). Historically in Xenopus tadpoles, swimming and struggling were thought to share similar synaptic drive and arise from a common circuitry, with struggling arising from additional neurons being added from within the same pool of shared cells (Soffe, 1993). Recent evidence includes the addition of two new specialized classes of very rostral excitatory interneurons recruited during struggling (Li et al., 2007), indicating that the network is not entirely shared with that used for swimming.

In our preparation we found that struggling involves both activity in cells that are shared with swimming, as well as in an additional, anatomically distinct class of commissural, glycinergic spinal interneuron, the CoLA cells, that was only active during struggling. The existence of such behavior specific neurons has also been documented in other aquatic vertebrates (Berkowitz, 2002). The anatomical and electrophysiological characteristics of CoLA interneurons indicate that they may be critical to the generation of struggling. Their long, commissural ascending axon and inhibitory phenotype are poised to generate an increase in rostral inhibition that could alter the excitability gradient along the body to establish greater caudal excitation, which might then cause the body wave to reverse and travel from tail to head. Shifting the rostrocaudal gradient of excitation pharmacologically or in modeling experiments in other species causes the body wave to propagate in the other direction by shortening rostral motor bursts (Tunstall and Roberts, 1994; Sigvardt and Williams, 1996; Green and Soffe, 1998; Yoshida et al., 1998). Crossed ascending inhibition has been shown previously to have a major influence on the struggling motor pattern in Xenopus (Green and Soffe, 1998). In support of a critical role for CoLAs in shaping struggling, we found that CoLAs always fired during struggling. In addition, their large somata (Hale et al., 2001) and high firing

Figure 6. CoBLs are largely shared between swimming and struggling. Ai, Depolarizing current injections showing tonic spiking once threshold is reached. Aii, Tracing of a COBL in a lateral view of spinal cord (rostral to the left) showing a characteristic contralateral bifurcation of the main axon into an ascending and descending projection (black portions are contralateral). $\boldsymbol{B i}$, CoBL somata are distributed widely across the dorsal half of the spinal cord with an average position of $73 \%$, where $100 \%$ represents the dorsal edge of the spinal cord. Bii, Pie chart showing that the majority of $\mathrm{CoBLs}(88 \%)$ are active during both swimming and struggling. Biii, Graph showing the percentage of times a cell fires during escapes (e; $3 \%$ ) swimming (sw; 49\%) and struggling (st; 81\%). C, Simultaneous motor root and whole-cell recordings during an escape behavior (arrow) initiated immediately after an electrical pulse (stimulus artifact). The CoBL does not fire in the initial escape burst or during the subsequent low frequency swimming episode. $\boldsymbol{D}$, The COBL fires action potentials that ride on top of a depolarized potential during the start of a swimming bout (relatively high frequency) but stops firing at lower swimming frequencies at the end of the bout (see Results, Activity in commissural bifurcating interneurons, for explanation). Stimulus is located to the left of trace (data not shown), $75 \mathrm{~ms}$ before first motor burst. $E$, The CoBL fires a long series of spikes during struggling bursts. Stimulus is located to the left of trace (data not shown), 53 ms before the first struggling motor burst. Duration of activity and spike number decreases as the motor pattern transitions from struggling (first four bursts) to swimming, and spiking stops completely during lower frequency swimming. $\boldsymbol{F}$, Plot of ventral motor root burst duration versus frequency for swimming (circles) and struggling (squares) for all cells for all trials. Black filled symbols indicate that the cell fired, while gray outlined symbols indicate that the cell did not fire. CoBLs were active over the range of burst characteristics for both swimming (duration range $=1-24 \mathrm{~ms}$ and frequency range $=$ $15-75 \mathrm{~Hz}$ ) and struggling (duration range $=13-46 \mathrm{~ms}$ and frequency range $=12-26 \mathrm{~Hz}$ ), and were most reliably activated at higher swimming frequencies. Inset graphs show that the average value \pm SD for swimming duration is shorter than for struggling $(6.3 \pm 3.7 \mathrm{~ms}$ vs $26.0 \pm 7.9 \mathrm{~ms}$ ). Average swimming frequency is higher than struggling ( $41.5 \mathrm{~Hz} \pm 13.4 \mathrm{vs} 18.8$ $\mathrm{Hz} \pm 3.4)$. All electrophysiology traces are from the same cell. 


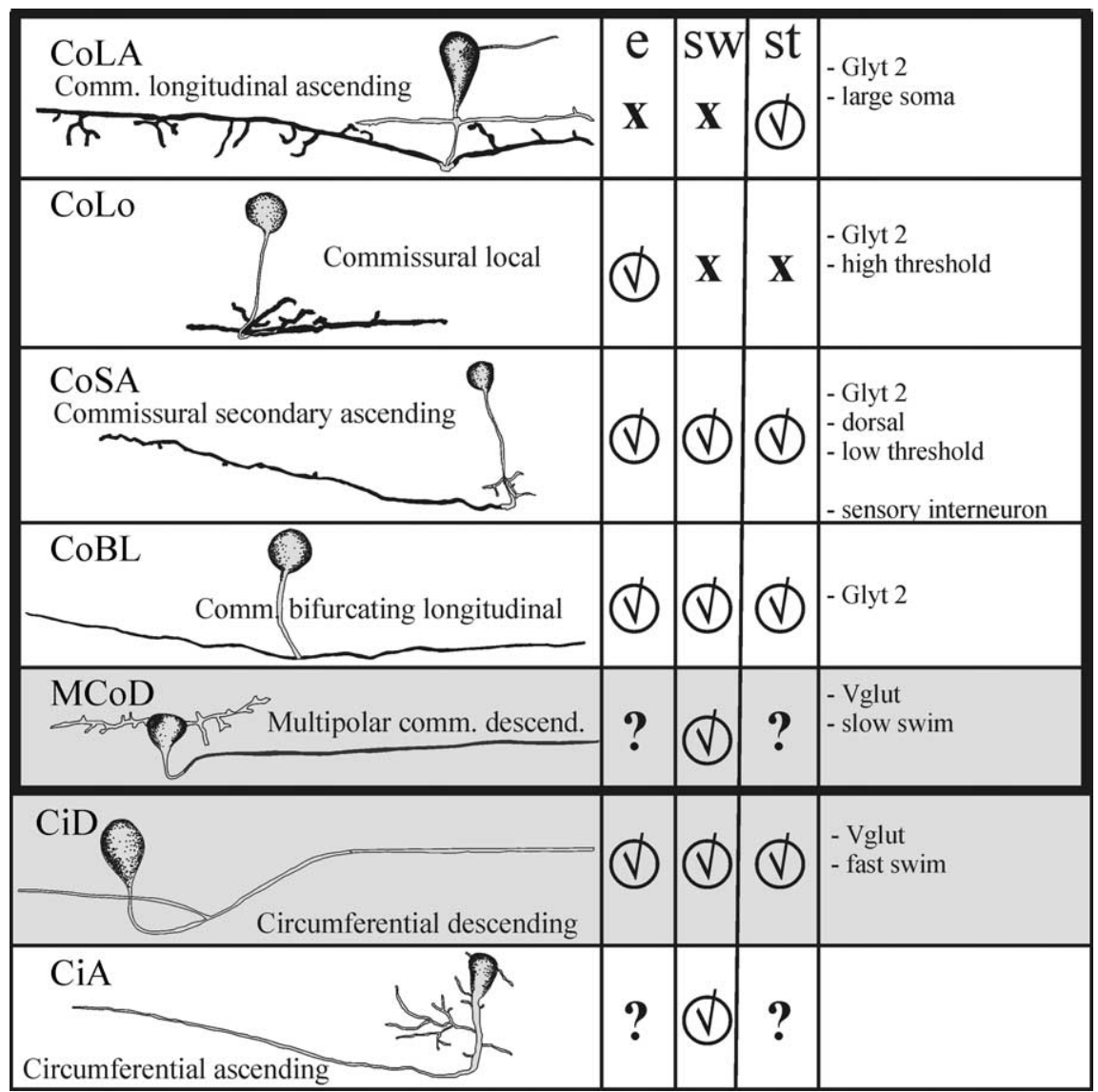

Figure 7. Current summary of inhibitory (white filled boxes) and excitatory (gray filled boxes) spinal interneuron activity during different axial motor patterns in larval zebrafish. The top five rows (bold box) illustrate commissural cell types where black fill represents the contralateral portions of the axon. The bottom two rows are ipsilateral interneurons. When known, transmitter phenotype and special attributes are indicated. Two interneuronal classes, both inhibitory, are each active during only one of three motor patterns tested in this study (CoLAs for struggling and CoLos for escapes). Some inhibitory (CoSAs, CoBLs) and excitatory (CiDs) interneurons are multifunctional and shared between all motor patterns, although their contribution can vary with frequency within a motor pattern. MCoDs are active in slow, but not fast swimming (McLean et al., 2007); their activity during escape and struggling are currently unknown. Circumferential ascending interneurons (CiAs) are inhibitory and make monosynaptic connections with sensory pathway neurons (Higashijima et al., 2004c) and motoneurons, potentially playing a role in sensory gating and burst termination. CiAs are active during swimming, but their contribution to struggling and escape behaviors remains unknown.

thresholds are consistent with our finding that high levels of excitatory drive are required to trigger struggling.

The CoLAs are not the only specialized cell type we found. The CoLo interneurons have a high firing threshold and are active only during escapes. Escapes differ dramatically from swimming and struggling in that escapes require a mechanism which produces a fast, nearly synchronous excitation on one side of spinal cord coincident with a powerful, short duration contralateral inhibition to block competing motor activity. Based upon their shared unique morphology and role in escapes, CoLos are probably the same cell type that provides short latency crossed inhibition previously described in the escape circuit of adult goldfish and tench, both closely related to zebrafish (Fetcho, 1990; Yasargil and Sandri, 1990). Their commissural axon has multiple processes near the Mauthner axon collaterals, indicating the potential for strong, local inhibitory effects.

Previous work showed that firing one M-axon electrotonically excites the CoLo-like cells in goldfish, in addition to exciting ipsilateral motoneurons (Fetcho and Faber, 1988). Crossed inhibition by these goldfish escape interneurons blocks excitation of contralateral motor neurons and excitatory interneurons, so that ipsilateral bending can proceed without interference from the opposite side. The goldfish work indicates that these interneurons also inhibit the same cell type on the contralateral side so that the contralateral inhibitory neurons do not interfere with ipsilateral motor neuron activation by the M-axon (Fetcho and Faber, 1988). By building a circuit with a series of short, inhibitory interneurons it is possible to generate short latency, but powerful inhibition through several interneurons converging onto one motoneuron. An alternative arrangement in which cells with long, intersegmental axons are used might lead to longer lasting, weaker inhibition (Fetcho, 1990). This could be problematic because to quickly alternate the body bends to swim away after escaping from a threatening stimulus, contralateral inhibition must be short to avoid delaying a subsequent bend to that side. Based on similarities between the swimming and escape network, our previous work predicted that these cell types in goldfish might be part of the swimming circuit, especially at high swimming speeds (Svoboda and Fetcho, 1996). If the goldfish escape interneurons are indeed CoLos, our new data indicate that this may be wrong. Even at the fastest swimming speeds we never found CoLo activity, indicating that swimming and escapes probably do not share all circuit components in the spinal cord.

In addition to these specialized glycinergic interneurons, we also found interneurons that were shared among behaviors. Ascending (CoSAs) and commissural bifurcating (CoBLs) interneurons were shared between both swimming and struggling, similar to the results of tadpole studies (Soffe, 1993; Yoshida et al., 1998; Li et al., 2007). CoSAs are clearly a complicated class of cells given the evidence for the expression of both excitatory and inhibitory phenotypes (Hale et al., 2001; Gleason et al., 2003; Higashijima et al., 2004c,b). We found that the majority of the time CoSAs fired during struggling, but that their firing frequency and pattern during swimming and escapes was variable. At slow swimming frequencies, some cells fired nonrhythmically or fired a single action potential at the beginning of a swimming bout. At faster swimming speeds, firing became rhythmic and lasted throughout the burst cycle. Although our picture of CoSAs is less clear than of other glycinergic cell types, what is evident from this study is that they are a cell type with a low firing threshold that can be active across behaviors or change firing pattern depending on the strength of input within a single behavior.

Multifunctional CoBLs have a more consistent pattern of activation than CoSAs. The overwhelming majority fire rhythmically during both swimming and struggling, CoBLs have shorter average axon lengths compared with most other rhythmic glycinergic cell types (the even shorter CoLos showed no rhythmicity), 
which may allow for local inhibition during alternating movements. We found CoBLs to be a very common cell type in our preparation and, combined with their ability to fire rhythmically to both swimming and struggling (unlike CoLAs and CoLos), they appear to be very good candidates for forming the core alternation of activity on the two sides shared by swimming and struggling motor patterns.

Although there are some shared interneuronal classes, the existence of specialized, glycinergic neurons indicates that there are fundamental aspects of motor patterns that probably cannot be accomplished by the same pool of spinal interneurons. How broad is this pattern, and what are the relationships between cell type and behavioral specificity when we look outside the subset of neurons that are glycinergic? Within excitatory interneurons, we find that cell types can be specialized even within a single behavior (Bhatt et al., 2007; McLean et al., 2007). Two anatomically distinct cell types have been shown to be active over different frequencies of swimming (McLean et al., 2007, 2008). Multipolar commissural descending interneurons (MCoDs) are active during low frequency swimming $(\sim 30 \mathrm{~Hz})$, but are inhibited at faster frequencies. In contrast, circumferential ipsilateral descending interneurons (CiDs) are predominantly active during faster swimming (Fetcho and Faber, 1988; Ritter et al., 2001; Bhatt et al., 2007). Although these cells types are specialized for different ends of the swimming frequency spectra, they both have the common feature of long descending axons (Hale et al., 2001). More needs to be known about the synaptic properties, postsynaptic targets, and conduction velocity of these specialized cell types to understand the basis for the switching of cell types with frequency. It might be important for the preservation of intersegmental coordination patterns across a broad range of swimming frequencies.

Figure 7 summarizes the current data regarding the involvement of spinal cell types in different axial motor patterns in zebrafish. Since most of the work leading to this table has focused on one region of the body, we cannot totally rule out a different pattern for cells at other regions. Nonetheless, the evidence from both inhibitory and excitatory neurons indicates that neurons with distinct morphologies may be called upon to sculpt unique rhythmic behaviors from a local segmental pattern of alternating bending. Specialized neurons are also engaged to produce high performance bending during escapes. Thus, the picture that is emerging in zebrafish, which is similar to that in turtles and frog tadpoles (Berkowitz, 2002, Li et al., 2007), is that particular motor behaviors do not arise simply from a pool of generalized, shared spinal neurons activated in different ways to produce different motor outputs. While there does appear to be a core of shared spinal neurons, the evidence suggests that motor output produced by these cells is shaped by specialized spinal neurons that are active only during one behavior. If this is the case, then blocking the function of a population of specialized neurons such as the CoLAs or CoLos we describe here by, for example, using light activated chloride pumps (Nagel et al., 2005), should abolish struggling or escapes while sparing other motor behaviors. This depends upon the eventual production of the appropriate transgenic lines, but would directly test the idea that some classes of interneurons are specialized and essential for the production of particular motor patterns.

\section{References}

Arber S, Han B, Mendelsohn M, Smith M, Jessell TM, Sockanathan S (1999) Requirement for the homeobox gene $\mathrm{Hb} 9$ in the consolidation of motor neuron identity. Neuron 23:659-674.

Berkowitz A (2002) Both shared and specialized spinal circuitry for scratch- ing and swimming in turtles. J Comp Physiol A Neuroethol Sens Neural Behav Physiol Neuroethol Sens Neural Behav Physiol 188:225-234.

Berkowitz A (2005) Physiology and morphology indicate that individual spinal interneurons contribute to diverse limb movements. J Neurophysiol 94:4455-4470.

Bernhardt RR, Chitnis AB, Lindamer L, Kuwada JY (1990) Identification of spinal neurons in the embryonic and larval zebrafish. J Comp Neurol 302:603-616.

Bhatt DH, McLean DL, Hale ME, Fetcho JR (2007) Grading movement strength by changes in firing intensity versus recruitment of spinal interneurons. Neuron 53:91-102.

Fetcho JR (1990) Morphological variability, segmental relationships, and functional role of a class of commissural interneurons in the spinal cord of goldfish. J Comp Neurol 299:283-298.

Fetcho JR (1992) The spinal motor system in early vertebrates and some of its evolutionary changes. Brain Behav Evol 40:82-97.

Fetcho JR, Faber DS (1988) Identification of motoneurons and interneurons in the spinal network for escapes initiated by the mauthner cell in goldfish. J Neurosci 8:4192-4213.

Gleason MR, Higashijima S, Dallman J, Liu K, Mandel G, Fetcho JR (2003) Translocation of CaM kinase II to synaptic sites in vivo. Nat Neurosci 6:217-218

Green CS, Soffe SR (1998) Roles of ascending inhibition during two rhythmic motor patterns in Xenopus tadpoles. J Neurophysiol 79: $2316-2328$.

Hale ME, Ritter DA, Fetcho JR (2001) A confocal study of spinal interneurons in living larval zebrafish. J Comp Neurol 437:1-16.

Higashijima S, Mandel G, Fetcho JR (2004a) Distribution of prospective glutamatergic, glycinergic, and GABAergic neurons in embryonic and larval zebrafish. J Comp Neurol 480:1-18.

Higashijima S, Schaefer M, Fetcho JR (2004b) Neurotransmitter properties of spinal interneurons in embryonic and larval zebrafish. J Comp Neurol 480:19-37.

Higashijima S, Masino MA, Mandel G, Fetcho JR (2004c) Engrailed-1 expression marks a primitive class of inhibitory spinal interneuron. J Neurosci 24:5827-5839.

Kristan WB Jr, Shaw BK (1997) Population coding and behavioral choice. Curr Opin Neurobiol 7:826-831.

Li WC, Sautois B, Roberts A, Soffe SR (2007) Reconfiguration of a vertebrate motor network: specific neuron recruitment and contextdependent synaptic plasticity. J Neurosci 27:12267-12276.

Liu KS, Fetcho JR (1999) Laser ablations reveal functional relationships of segmental hindbrain neurons in zebrafish. Neuron 23:325-335.

Marder E, Calabrese RL (1996) Principles of rhythmic motor pattern generation. Physiol Rev 76:687-717.

McLean DL, Fan J, Higashijima S, Hale ME, Fetcho JR (2007) A topographic map of recruitment in spinal cord. Nature 446:71-75.

McLean DL, Masino MA, Koh IYY, Lindquist WB, Fetcho JR (2008) Continuous switches in the active set of spinal interneurons drive changes in locomotor speed. Nat Neurosci. Advance online publication. Retrieved November 14, 2008. doi: 10.1038/nn.2225

Morton DW, Chiel HJ (1994) Neural architectures for adaptive behavior. Trends Neurosci 17:413-420.

Nagel G, Brauner M, Liewald JF, Adeishvili N, Bamberg E, Gottschalk A (2005) Light activation of channelrhodopsin-2 in excitable cells of Caenorhabditis elegans triggers rapid behavioral responses. Curr Biol 15:2279-2284.

Ritter DA, Bhatt DH, Fetcho JR (2001) In vivo imaging of zebrafish reveals differences in the spinal networks for escape and swimming movements. J Neurosci 21:8956-8965.

Roberts A, Tunstall MJ (1994) Longitudinal gradients in the spinal cord of Xenopus embryos and their possible role in coordination of swimming. Eur J Morphol 32:176-184.

Roberts A, Walford A, Soffe SR, Yoshida M (1999) Motoneurons of the axial swimming muscles in hatchling Xenopus tadpoles: features, distribution, and central synapses. J Comp Neurol 411:472-486.

Shaw BK, Kristan WB Jr (1997) The neuronal basis of the behavioral choice between swimming and shortening in the leech: control is not selectively exercised at higher circuit levels. J Neurosci 17:786-795.

Sigvardt KA, Williams TL (1996) Effects of local oscillator frequency on intersegmental coordination in the lamprey locomotor CPG: theory and experiment. J Neurophysiol 76:4094-4103. 
Sillar KT, Roberts A (1992) The role of premotor interneurons in phasedependent modulation of a cutaneous reflex during swimming in Xenopus laevis embryos. J Neurosci 12:1647-1657.

Soffe SR (1993) Two distinct rhythmic motor patterns are driven by common premotor and motor neurons in a simple vertebrate spinal cord. J Neurosci 13:4456-4469.

Svoboda KR, Fetcho JR (1996) Interactions between the neural networks for escape and swimming in goldfish. J Neurosci 16:843-852.

Tunstall MJ, Roberts A (1991) Longitudinal coordination of motor output during swimming in Xenopus embryos. Proceedings of the Royal Society of London: Biological Sciences 244:27-32.

Tunstall MJ, Roberts A (1994) A longitudinal gradient of synaptic drive in the spinal cord of Xenopus embryos and its role in coordination of swimming. J Physiol 474:393-405.

Xin Y, Weiss KR, Kupfermann I (1996) An identified interneuron contributes to aspects of six different behaviors in Aplysia. J Neurosci 16:5266-5279.

Yasargil GM, Sandri C (1990) Topography and ultrastructure of commissural interneurons that may establish reciprocal inhibitory connections of the Mauthner axons in the spinal cord of the tench, Tinca tinca L. J Neurocytol 19:111-126.

Yoshida M, Roberts A, Soffe SR (1998) Axon projections of reciprocal inhibitory interneurons in the spinal cord of young Xenopus tadpoles and implications for the pattern of inhibition during swimming and struggling. J Comp Neurol 400:504-518. 